\title{
TRATAMENTO UNIDOMICILIAR DE ÁGUA PARA O SEMIÁRIDO SOB CONDIÇÕES DE SECAS
}

Gleiciane dos Santos Gomes - gleiciane28@ outlook.com

Universidade Federal do Ceará (UFC)

Fernando Soares de Sousa Matos - fernandosdsmatos@gmail.com

Universidade Federal do Ceará (UFC)

Leonardo Vieira Melo Freire - leo_spj@ hotmail.com

Universidade Federal do Ceará (UFC)

José Carlos de Araújo - jcaraujo@ufc.br

Universidade Federal do Ceará (UFC) 


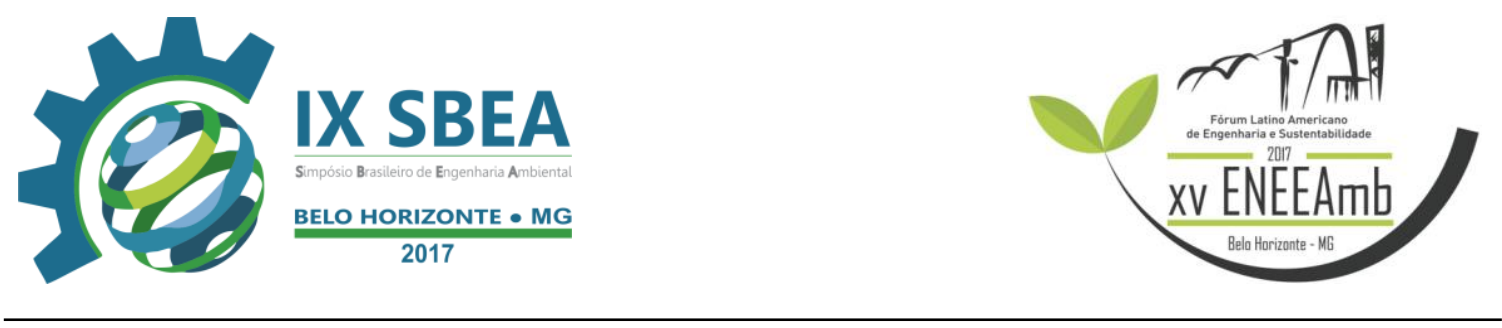

\section{RESUMO}

Devido à escassez e contaminação dos poucos corpos hídricos existentes na região semiárida sob condição de seca, principalmente de seca plurianual (2012 - 2016: de Araújo e Bronstert, 2016), busca-se estudar e desenvolver formas alternativas de tratamento da água que auxiliem a população a ter acesso a modelos que aperfeiçoem o seu fornecimento. A utilização de Moringa Oleífera juntamente com à tecnologia de desinfecção solar da água (SODIS) pode surgir como uma alternativa para esse cenário, visto que a Moringa Oleífera é um coagulante natural facilmente encontrado na região, e o sol é uma fonte natural, universalmente disponível e gratuita, tanto de calor como de luz. A presente pesquisa foi realizada no Assentamento 25 de Maio, em Madalena, Ceará, no período de julho a dezembro de 2016; visando o tratamento da água de pequenos reservatórios (açudes), após cinco anos de seca. Os resultados indicaram que o tratamento proposto reduziu $88 \%$ da turbidez e $89 \%$ de coliformes termotolerantes. Não houve, entretanto, êxito na redução da DBO. A água tratada não obedeceu à legislação no que se refere à potabilidade, principalmente pela pouca eficiência da filtração, causada pelo excesso de microalgas.

Palavras-chave: Solução coagulante, Moringa Oleífera, SODIS.

\section{OBJETIVO}

Desenvolver um sistema de tratamento de água unidomiciliar sustentável, e eficaz que ajude a população rural em um período prolongado de estiagem. Logo, a pesquisa busca proporcionar a população do semiárido melhores condições de saúde e de vida.

\section{METODOLOGIA}

A área de estudo foi o assentamento 25 de Maio, a $184 \mathrm{~km}$ de Fortaleza. É situado no Sertão Central do Estado do Ceará entre os municípios de Madalena, Boa Viagem e Quixeramobim com uma área ocupada de aproximadamente $230 \mathrm{~km}^{2}$. Ao todo, no local, existem onze pequenos açudes com capacidades entre 60 mil e 5 milhões de $\mathrm{m}^{3}$, e um açude de médio porte denominado de Quieto ou Marengo, com aproximadamente $15 \mathrm{hm}^{3}$. Todos estão situados na sub-bacia do rio Banabuiú, pertencente à bacia do rio Jaguaribe 


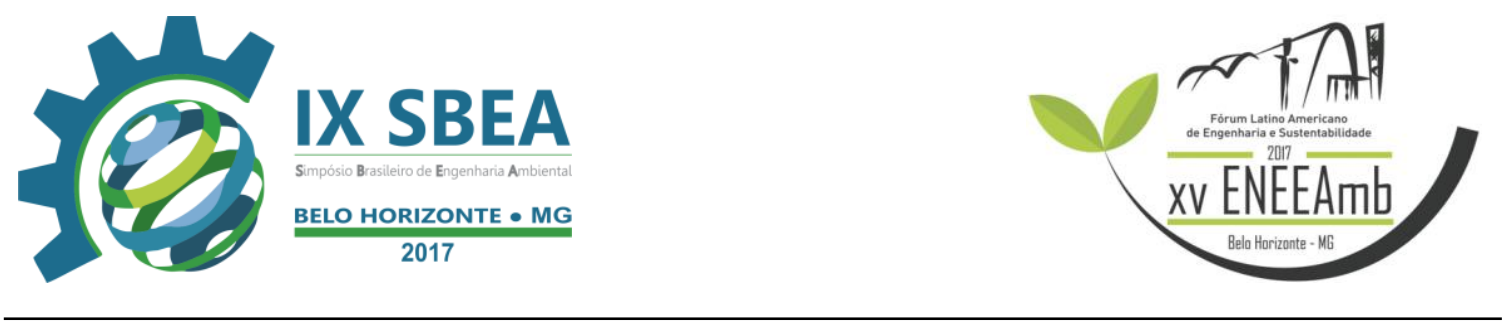

(ACACE, 2005; COELHO, 2013). A escolha do açude Quieto está associada à sua capacidade de atender à demanda por maior tempo do que os demais no entorno, por ser o único de médio porte e que não secou totalmente por causa da seca plurianual que teve início em 2012 e perdurou, pelo menos, até 2016 (DE ARAÚJO E BRONSTERT, 2016).

A parte experimental da pesquisa, para o tratamento da água no açude Quieto, contemplou três etapas fundamentais: a clarificação, a filtração e a desinfecção. Inicialmente, a etapa de clarificação, que compreendeu às fases de coagulação, floculação e decantação, processou o coagulante natural. Na etapa seguinte foi utilizado o filtro de barro, equipamento comumente encontrado nas residências, para remover os microrganismos por meio da filtração. Por fim, à desinfecção solar, última e terceira etapa, foi outra barreira de proteção contra patógenos no sistema, através da tecnologia SODIS.

A metodologia analítica visou à caracterização das seguintes variáveis limnológicas: pH, Turbidez, Demanda Bioquímica de Oxigênio (DBO) e Coliformes Termotolerantes (CTT). Foram usados os métodos analíticos, conforme descrito no Standard Methods for the Examination of Water and Wastewater de autoria das instituições American Public Health Association (APHA), American Water Works Association (AWWA) e Water Environment Federation (WEF).

As sementes da Moringa Oleífera, utilizadas no processo de coagulação, foram coletadas na da Faculdade de Educação da Universidade Federal do Ceará em suas vagens para posteriormente serem descascadas, contadas, trituradas e solubilizadas em água destilada para preparar o coagulante natural para o tratamento da água bruta.

Inicialmente o experimento foi realizado com três concentrações de moringa distintas para se chegar à quantidade ótima a ser utilizada no tratamento. A metodologia utilizada para a escolha das três concentrações distintas teve como base a utilizada por Folkard et al (1999), a partir da turbidez inicial da água bruta. Chamou-se de C1 (32g/L) o valor corresponde à metade do disposto na literatura, o valor da literatura foi chamado de C2 $(64 \mathrm{~g} / \mathrm{L})$ e o dobro deste valor recomendando foi nomeado $\mathrm{C} 3$, gerando a concentração de $128 \mathrm{~g} / \mathrm{L}$ de moringa em água destilada. 


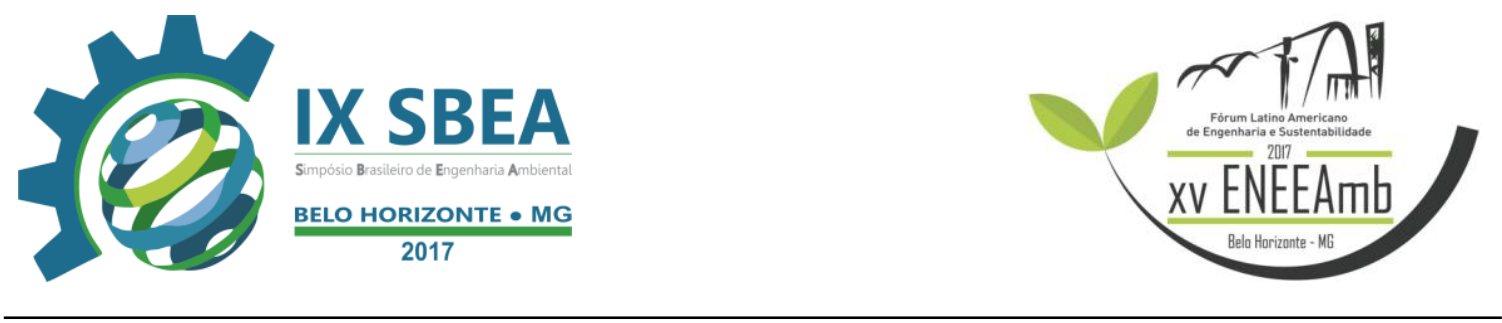

No processo de filtração, o material utilizado foi o filtro de barro, para reter as impurezas que até então não haviam sido retiradas. Cada solução de concentração inicial (C1, C2 e C3), anteriormente mencionada, possuía o seu respectivo filtro.

Em relação ao SODIS, por meio da exposição solar da água em garrafas transparentes promoveu-se a inativação microbiana (MOREIRA; PATERNIANI, 2005). O tempo estimado para a etapa do tratamento foi de 6 horas no intervalo de tempo no qual a incidência dos raios ultravioletas era mais intensa, entre as 09:00 e 15:00hrs (MEIERHOFER, R. e WEGELIN, M., 2002).

\section{RESULTADOS E DISCUSSÃO}

Os resultados apresentados nos gráficos abaixo são referentes às médias das coletas realizadas nos meses de julho, setembro, outubro, novembro e dezembro do ano 2016 de acordo com os parâmetros escolhidos para a presente pesquisa.

As análises dos parâmetros pH, turbidez, DBO, e CTT da água bruta, em comparação ao Valor Máximo Permitido (VMP) exigido pela Resolução CONAMA 357/05, Portaria do Ministério da Saúde (MS) 2914/11 e Organização Mundial Saúde (OMS) mostraram-se positivas tanto para a etapa de clarificação (C1, C2 e C3) como para a etapa de desinfecção (D1, D2 e D3).

\section{POTENCIAL HIDROGENIÔNICO}

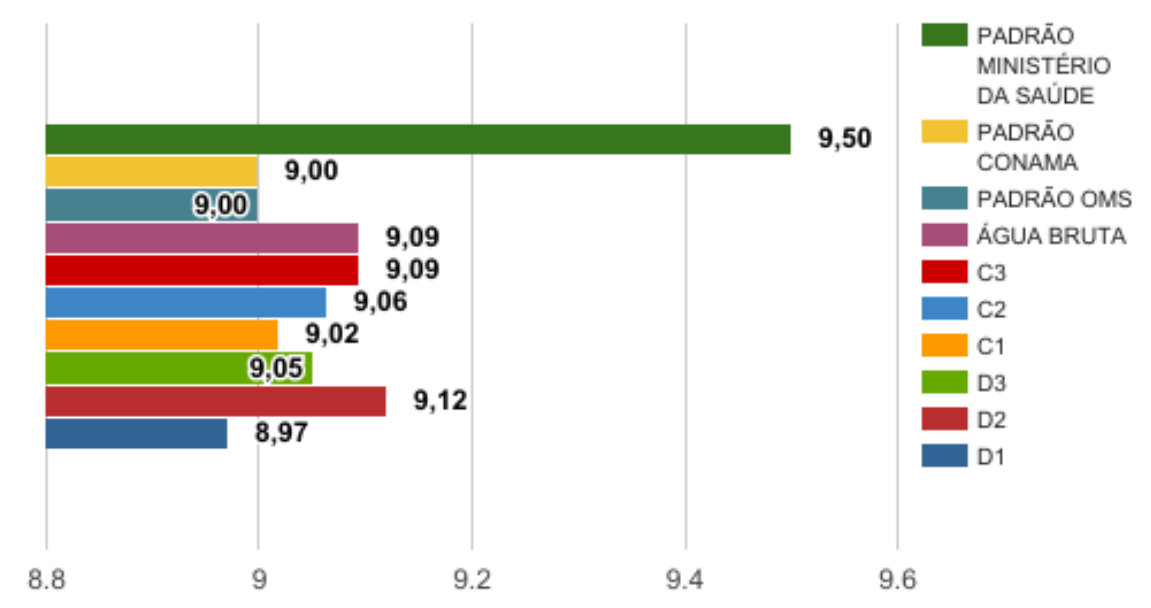


TURBIDEZ

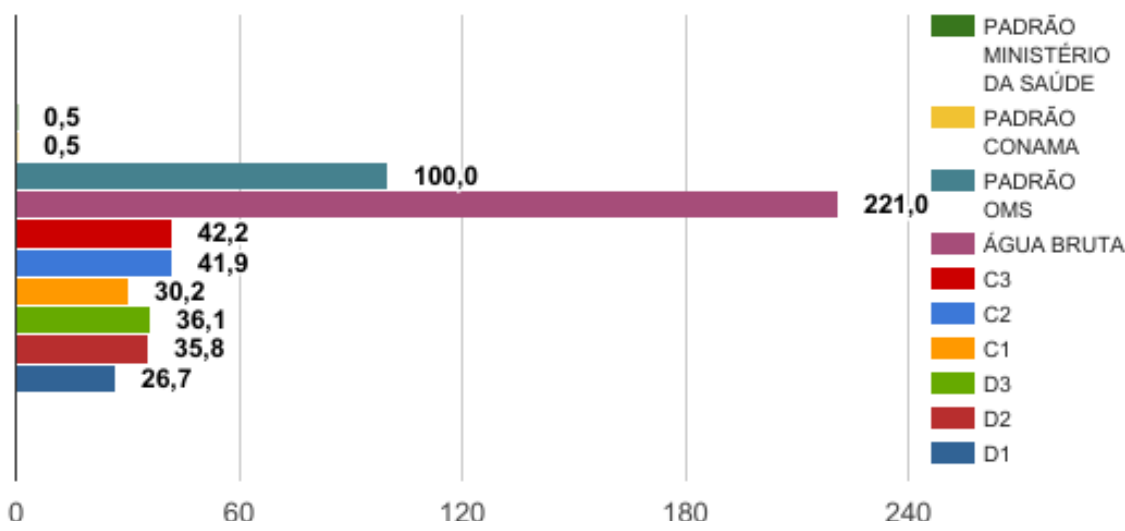

\section{COLIFORMES TERMOTOLERANTES}

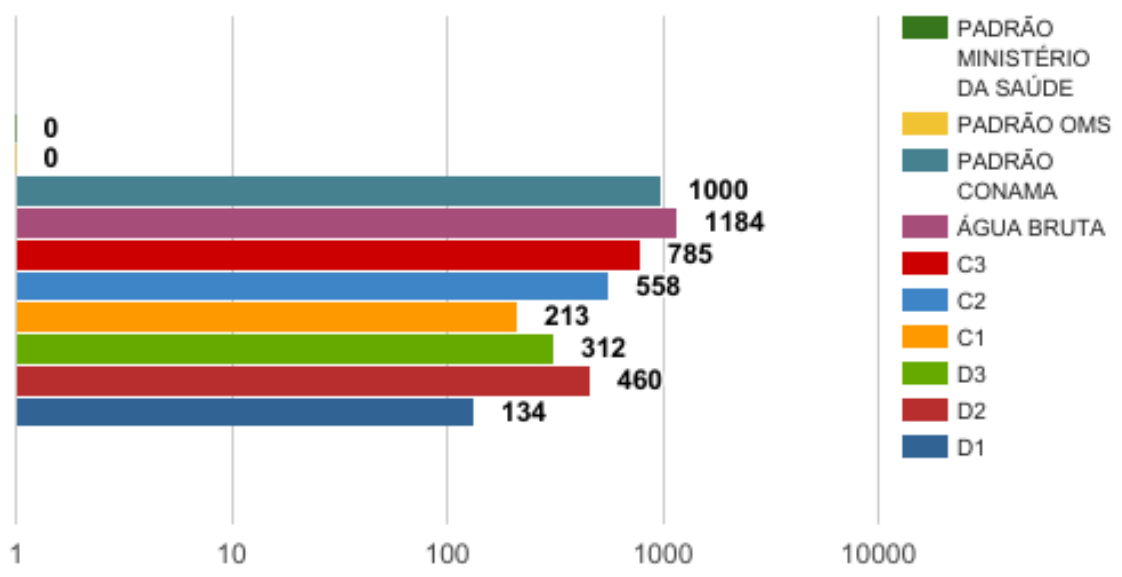

\section{DEMANDA BIOLÓGICA DE OXIGÊNIO}

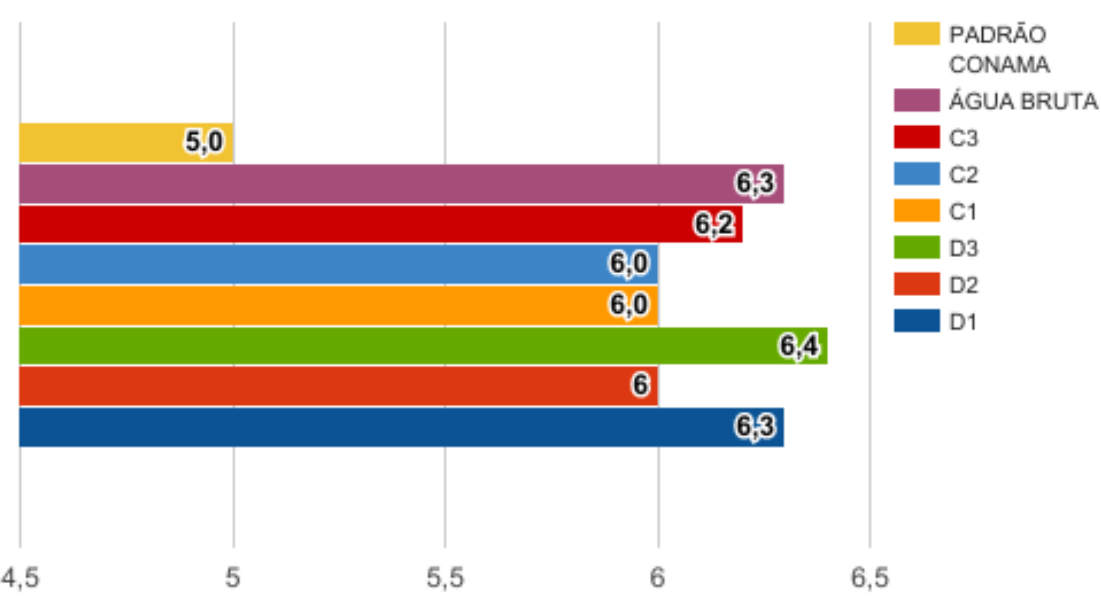

OBS:NAS NORMAS REGULADORAS DA OMS E DO MINISTÉRIO DA SAÚDE NÃO CONSTAM VALORES PARA DBO 


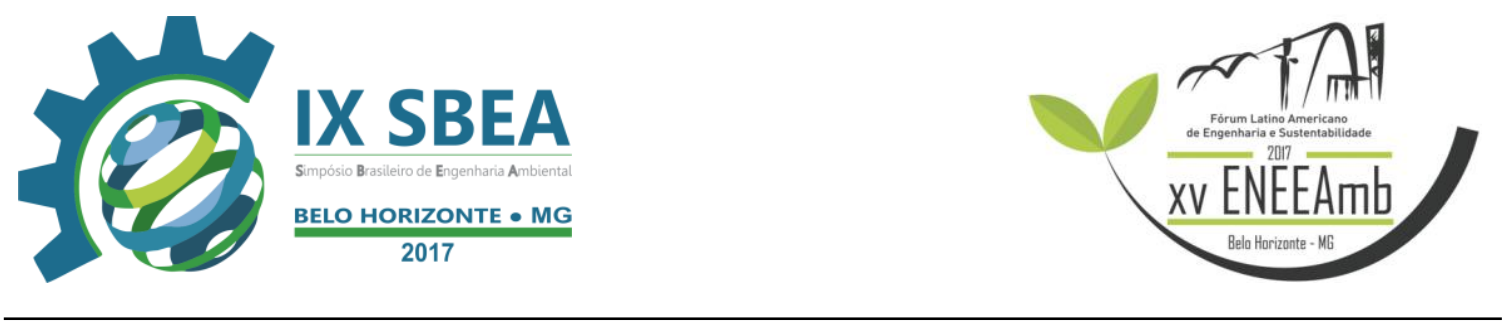

O parâmetro pH possui uma característica mais alcalina por estar acima da referência de neutralidade $(\mathrm{pH}=7)$. Com a diminuição da acidez da água, na qual o pH está em níveis mais altos com leve caráter alcalino, se pode afirmar que a concentração de oxigênio dissolvido está elevada, pois a concentração de dióxido de Carbono $\left(\mathrm{CO}_{2}\right)$ na água diminui, fazendo com que a formação de ácido carbônico ocorra em menor frequência. A concentração C1 obteve uma eficiência da qualidade da água de $1 \%$ quando comparada a água bruta tanto antes como após à etapa de desinfecção por radiação solar (SODIS). Já as concentrações C2 e C3 obtiveram $0 \%$.

A turbidez assume grande importância por razões relacionadas a processos de tratamento, especificamente na filtração e na desinfecção por razões de obstrução da passagem de água e luz. Se comparadas às amostras antes e após o processo, a redução da turbidez, que é um parâmetro esteticamente observável, obteve significativa redução. Para a $\mathrm{C} 1$, à redução da turbidez foi de $86 \%$, para $\mathrm{C} 2$ foi de $81 \%$, e, por fim, em C3 à redução foi de $81 \%$. Já após à etapa de desinfecção houve uma maior eficiência do processo, para D1, à redução da turbidez foi de $88 \%$, em D2 foi de $84 \%$ e D3 foi de $84 \%$.

O parâmetro CTT é muito importante em um processo de desinfecção visto que, quanto maior à população de coliformes em uma amostra de água, maior é a chance de contaminação por organismos patogênicos (BRASIL, 2014). A eficiência do processo na eliminação dos coliformes termotolerantes foi melhor observada na concentração 1 tanto na etapa de clarificação (C1) como na de desinfecção (D1) que foram $82 \%$ e $89 \%$, respectivamente. Já para C2 a eficiência do processo foi de 53\%, em C3 foi 34\% e nas etapas de desinfecção D2 e D3 foram 61\% e 74\%, respectivamente.

A análise da DBO é amplamente utilizada para determinar o potencial da poluição de águas residuárias, sendo um dos mais importantes parâmetros para às atividades de controle da poluição de cursos d'água, além de ser indispensável nos trabalhos de regulamentação da qualidade de efluentes e em estudos para avaliar a capacidade de depuração dos corpos d'água receptores de despejos. A DBO elevada significa presença de poluição através da matéria orgânica proveniente de fontes pontuais e/ou difusas como pode ser observado no gráfico de DBO, onde se observa que ela está acima do valor máximo permitido mesmo após a realização de todo o processo. Entretanto, houve uma melhoria da água tratada pelo processo quando comparada a água bruta. 


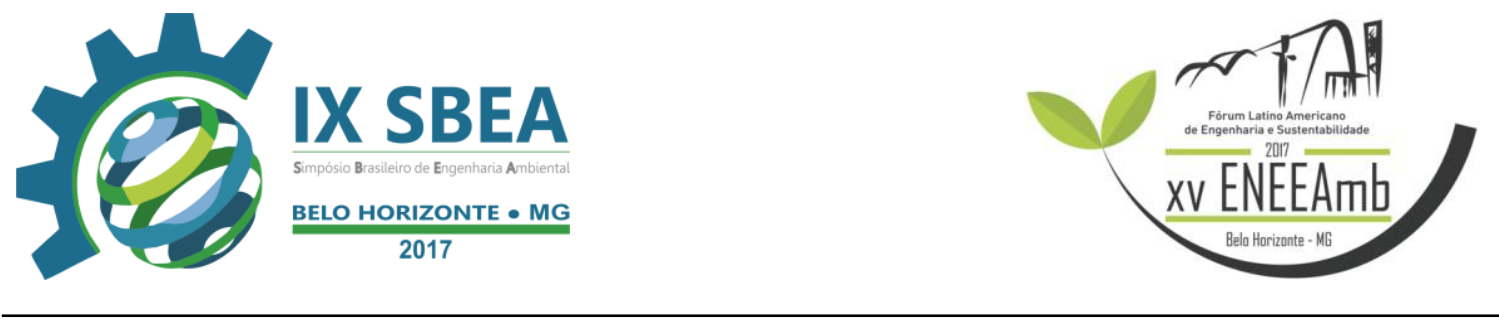

\section{CONCLUSÕES/RECOMENDAÇÕES}

De acordo com às análises realizadas e com os resultados obtidos pode-se concluir que a solução coagulante que melhor tratou à amostra de água bruta foi aquela preparada com a menor concentração de Moringa (32g/L). Entretanto à filtração é retardada, pela excessiva quantidade de microalgas.

O tratamento aplicado, ao final da etapa de desinfecção, reduziu a turbidez em $88 \%$ e os coliformes termotolerantes em $89 \%$. Não houve, entretanto, êxito na redução da DBO. A água tratada não obedeceu à legislação no que se refere à potabilidade.

\section{REFERÊNCIAS BIBLIOGRÁFICAS}

ACACE. Projeto de recuperação de Assentamento São Joaquim. Madalena: 2005.

APHA, AWWA, WCPF. Standard methods for examination of the water and wastewater, Washington, D.C.: American Public Health Association, Water Pollution Control Federation, 2005, 1134p.

BRASIL, Ministério da Saúde. Fundação Nacional de Saúde. Manual de controle e qualidade de água par técnicos que trabalham em ETAS. Brasília: FUNASA, 2014.

COELHO, C. F. Impactos socioambientais e desempenho da fossa verde no Assentamento 25 de Maio, Madalena (Ceará). 2013. Universidade Federal do Ceará. Dissertação (Mestrado).

CONAMA - CONSELHO NACIONAL DO MEIO AMBIENTE. Resolução no 357, de 17 de março de 2005: dispõe sobre a classificação dos corpos de água e diretrizes ambientais para o seu enquadramento, bem como estabelece as condições e padrões de lançamento de efluentes, e dá outras providências. Disponível em: <http://www.mma.gov.br/port/conama/legiabre.cfmcodlegi=459>. Acesso em: 16 de novembro de 2015.

de Araújo, J. C.; BRONSTERT, A. . A method to assess hydrological drought in semiarid environments and its application to the Jaguaribe River basin, Brazil. Water International, v. 41, p. 213-230, 2016

FOLKARD, G., SUTHERLAND, J. and SHAW R. Water Clarification using Moringa oleifera Seed Coagulant. Waterlines. Vol 17: pages 109-112. 1999.

MEIERHOFER, R. e WEGELIN, M. Desinfecção solar da água: guia de aplicações do SODIS. Dübendorf, 2002. 


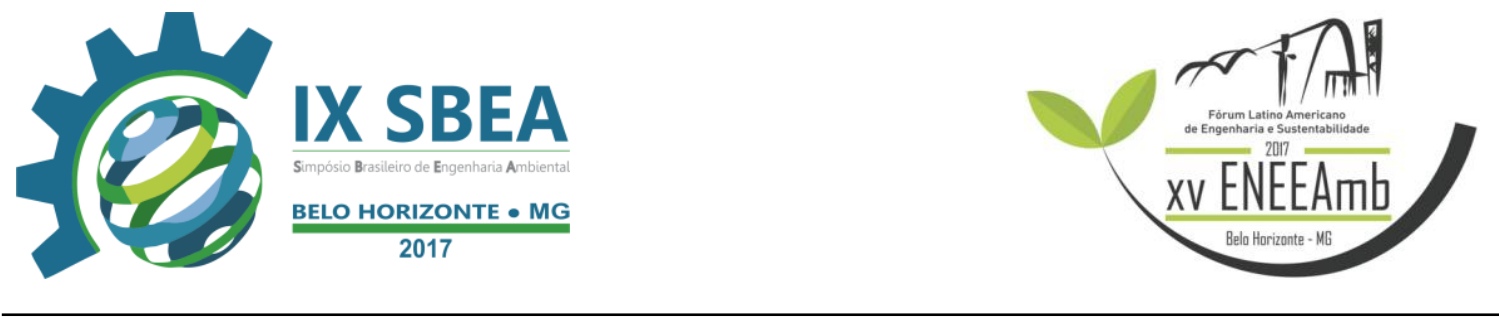

MOREIRA,M. J., PETERNIANI, J. E. S. Uso de garrafas pet e energia solar na desinfecção de águas em comunidades rurais. Eng. Ambiente. - Espírito Santo do Pinhal, v.2, n.1, p. 060-069, jan/dez 2005. 